\title{
Randomized controlled clinical trial of digital and conventional workflows for the fabrication of zirconia-ceramic fixed partial dentures. Part III: Marginal and internal fit
}

\author{
Benic, Goran I ; Sailer, Irena ; Zeltner, Marco ; Gütermann, Janine N ; Özcan, Mutlu ; Mühlemann, \\ Sven
}

\begin{abstract}
STATEMENT OF PROBLEM Trials comparing the overall performances of digital and conventional workflows in restorative dentistry are lacking. PURPOSE The purpose of the third part of this clinical study was to test whether the fit of zirconia 3-unit frameworks for fixed partial dentures fabricated with fully digital workflows differed from that of metal frameworks fabricated with the conventional workflow. MATERIAL AND METHODS In each of 10 participants, 4 fixed-partial-denture frameworks were fabricated for the same abutment teeth according to a randomly generated sequence. Digital workflows were applied for the fabrication of 3 zirconia frameworks with Lava, iTero, and Cerec infiniDent systems. The conventional workflow included a polyether impression, manual waxing, the lostwax technique, and the casting of a metal framework. The discrepancies between the frameworks and the abutment teeth were registered using the replica technique with polyvinyl siloxane. The dimensions of the marginal discrepancy (Discrepancy) and the internal discrepancy in 4 different regions of interest (Discrepancy, Discrepancy, Discrepancy, and Discrepancy) were assessed using a light microscope. Post hoc t tests with Bonferroni correction were applied to detect differences ( =.05). RESULTS Discrepancy was $96.1 \pm 61.7 \mathrm{~m}$ for the iTero, $106.9 \pm 96.0 \mathrm{~m}$ for the Lava, $112.2 \pm 76.7 \mathrm{~m}$ for the Cerec infiniDent, and $126.5 \pm 91.0 \mathrm{~m}$ for the conventional workflow. The difference between the iTero and the conventional workflow was statistically significant $(\mathrm{P}=.029)$. Discrepancy was $153.5 \pm 66.8 \mathrm{~m}$ for the iTero, 203.3 $\pm 127.9 \mathrm{~m}$ for the Lava, $179.7 \pm 63.1 \mathrm{~m}$ for the Cerec infiniDent, and $148.8 \pm 66.8 \mathrm{~m}$ for the conventional workflow. Discrepancy was significantly lower for the conventional workflow than for the Lava and the Cerec infindent workflows $(\mathrm{P}<.01)$. The iTero resulted in significantly lower values of Discrepancy than the Lava and the Cerec infiniDent workflows $(\mathrm{P}<.01)$. CONCLUSIONS In terms of framework fit in the region of the shoulder, digitally fabricated zirconia 3-unit frameworks presented similar or better fit than the conventionally fabricated metal frameworks. In the occlusal regions, the conventionally fabricated metal frameworks achieved a more favorable fit than the CAD-CAM zirconia frameworks.
\end{abstract}

DOI: https://doi.org/10.1016/j.prosdent.2018.05.014

Posted at the Zurich Open Repository and Archive, University of Zurich

ZORA URL: https://doi.org/10.5167/uzh-159415

Journal Article

Accepted Version

Originally published at:

Benic, Goran I; Sailer, Irena; Zeltner, Marco; Gütermann, Janine N; Özcan, Mutlu; Mühlemann, Sven (2019). Randomized controlled clinical trial of digital and conventional workflows for the fabrication 
of zirconia-ceramic fixed partial dentures. Part III: Marginal and internal fit. Journal of Prosthetic Dentistry, 121(3):426-431.

DOI: https://doi.org/10.1016/j.prosdent.2018.05.014 
JPD-17-923

\section{CLINICAL RESEARCH}

Randomized controlled clinical trial of digital and conventional workflows for the fabrication of zirconia-ceramic fixed partial dentures. Part III: Marginal and internal fit

Goran I. Benic, PD Dr med dent, ${ }^{\mathrm{a}}$ Irena Sailer, Prof Dr med dent, ${ }^{\mathrm{b}}$ Marco Zeltner, Dr med dent, ${ }^{\mathrm{c}}$ Janine N. Gütermann, ${ }^{\mathrm{d}}$ Mutlu Özcan, Prof(NL) Dr med dent, ${ }^{\mathrm{e}}$ and Sven Mühlemann, Dr med $\operatorname{dent}^{\mathrm{f}}$

Supported by the Clinic of Fixed and Removable Prosthodontics and Dental Material Science, Center of Dental Medicine, University of Zurich, Switzerland and by a research grant from Institut Straumann AG, Basel, Switzerland.

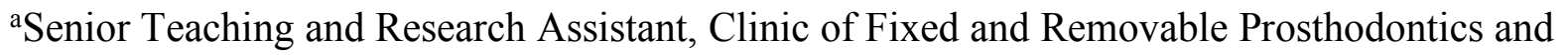
Dental Material Science, Center of Dental Medicine, University of Zurich, Zurich, Switzerland.

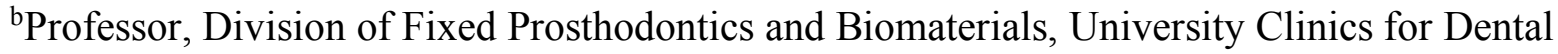
Medicine, University of Geneva, Geneva, Switzerland.

${ }^{\mathrm{c}}$ Senior Teaching and Research Assistant, Clinic of Fixed and Removable Prosthodontics and Dental Material Science, Center of Dental Medicine, University of Zurich, Zurich, Switzerland. ${ }^{\mathrm{d}}$ Master of Dental Medicine, Clinic of Fixed and Removable Prosthodontics and Dental Material Science, Center of Dental Medicine, University of Zurich, Zurich, Switzerland.

eProfessor, Clinic of Fixed and Removable Prosthodontics and Dental Material Science, Center of Dental Medicine, University of Zurich, Zurich, Switzerland. 
fSenior Teaching and Research Assistant, Clinic of Fixed and Removable Prosthodontics and Dental Material Science, Center of Dental Medicine, University of Zurich, Zurich, Switzerland.

\section{ABSTRACT}

Statement of problem. Trials comparing the overall performances of digital and conventional workflows in restorative dentistry are lacking.

Purpose. The purpose of the third part of this clinical study was to test whether the fit of zirconia 3-unit frameworks for fixed partial dentures (FPDs) fabricated with fully digital workflows differed from that of metal frameworks fabricated with the conventional workflow.

Material and methods. In each of 10 participants, 4 FPD frameworks were fabricated for the same abutment teeth according to a randomly generated sequence. Digital workflows were applied for the fabrication of 3 zirconia frameworks with Lava, iTero, and Cerec infiniDent systems. The conventional workflow included a polyether impression, manual waxing, the lostwax technique, and the casting of a metal framework. The discrepancies between the frameworks and the abutment teeth were registered using the replica technique with polyvinyl siloxane. The dimensions of the marginal discrepancy (Discrepancymarginal) and the internal discrepancy in 4 different regions of interest (Discrepancy shoulder, Discrepancyaxial, Discrepancy $_{\text {cusp }}$, and

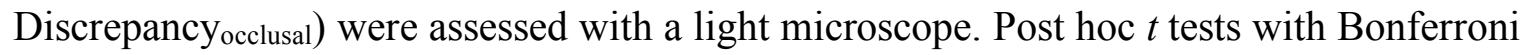
correction were applied to detect differences $(\alpha=.05)$.

Results. Discrepancyshoulder was $96.1 \pm 61.7 \mu \mathrm{m}$ for the iTero, $106.9 \pm 96.0 \mu \mathrm{m}$ for the Lava, 112.2 $\pm 76.7 \mu \mathrm{m}$ for the Cerec infiniDent, and $126.5 \pm 91.0 \mu \mathrm{m}$ for the conventional workflow. The difference between the iTero and the conventional workflow was statistically significant $(P$ $=.029$ ). Discrepancy occlusal was $153.4 \pm 49.0 \mu \mathrm{m}$ for the iTero, $203.3 \pm 127.9 \mu \mathrm{m}$ for the Lava, 
$179.7 \pm 63.0 \mu \mathrm{m}$ for the Cerec infiniDent, and $148.8 \pm 66.8 \mu \mathrm{m}$ for the conventional workflow. Discrepancy $_{\text {occlusal }}$ was significantly lower for the conventional workflow than for the Lava and the Cerec infindent workflows $(P<.01)$. The iTero resulted in significantly lower values of Discrepancy $y_{\text {occlusal }}$ than the Lava and the Cerec infiniDent workflows $(P<.01)$.

Conclusions. In terms of framework fit in the region of the shoulder, digitally fabricated zirconia 3-unit frameworks presented similar or better fit than the conventionally fabricated metal frameworks. In the occlusal regions, the conventionally fabricated metal frameworks achieved a more favorable fit compared with the CAD-CAM zirconia frameworks.

\section{CLINICAL IMPLICATIONS}

Digitally fabricated zirconia frameworks for 3-unit fixed dental prostheses have similar or better marginal fit than that of conventionally fabricated metal frameworks. In terms of internal fit in the occlusal regions, conventionally fabricated metal frameworks are better than zirconia frameworks fabricated with a digital workflow.

\section{INTRODUCTION}

The introduction of computer-aided design and computer-aided manufacturing (CAD-CAM) systems has led to dentistry with increased production efficiency and the introduction of new restorative materials, such as zirconia. Zirconia, because of its excellent mechanical characteristics, is a suitable alternative to the traditionally used metal frameworks for posterior fixed partial dentures (FPDs). ${ }^{1-4}$

An essential aspect of any restorative workflow is the marginal and internal fit of the resulting prosthesis. Poorly fitting margins are associated with a risk of caries through increased plaque 
accumulation and microleakage. ${ }^{5,6}$ Internal fit can influence the mechanical stability of the ceramic restoration, and an increased internal discrepancy can reduce retention and increase the incidence of ceramic fractures. ${ }^{7,8}$

The accuracy of CAD-CAM fabricated FPDs has been investigated in clinical and in vitro investigations. ${ }^{9-13}$ A systematic review ${ }^{14}$ assessed the accuracy of zirconia FPDs and revealed a wide range in the results. However, direct comparison between the systems was difficult because of the heterogeneity of the experimental protocols in the included studies. Evidence from clinical studies comparing the fit of digitally fabricated zirconia FPDs to that of conventionally fabricated FPDs with metal framework is sparse.

The present randomized controlled clinical trial was designed to compare the overall performance of 3 digital and 1 conventional workflow for the fabrication of tooth-supported 3unit FPDs, from the impression to the delivery of the restoration. A design with intrasubject comparison was used to reduce the influence of the confounding factors on the study outcome. Part I of the investigation assessed digital and conventional impressions with respect to time effectiveness and the perception of both the participants and operators. ${ }^{15}$ Part II analyzed the time effectiveness in the dental technical workflows. ${ }^{16}$ The purpose of part III was to test whether digital workflows used for the fabrication of zirconia frameworks for posterior 3-unit FPDs give different results from the conventional fabrication of metal frameworks with respect to marginal and internal fit.

\section{MATERIAL AND METHODS}

This study was designed as a blinded, randomized controlled clinical trial with within-subject comparison of 3 digital and 1 conventional workflow for the fabrication of tooth-supported 3- 
unit FPDs. The study was performed at the Clinic of Fixed and Removable Prosthodontics and Dental Material Science, Center of Dental Medicine, University of Zurich, Zurich, Switzerland. The trial was approved by the local ethical committee (ref. KEK-ZH-Nr. 2011-0103/5; Kantonale Ethik-Kommission, Zurich, Switzerland). The present study follows the methods and materials of a previous series of RCTs comparing the digital and conventional workflows for the fabrication of single crowns. ${ }^{17-19}$

Ten participants each in need of a 3-unit tooth-supported posterior FPD were included in the study. The inclusion criteria were reported in part I of this investigation. ${ }^{15}$ Written informed consent was obtained from all those participating. For each participant, 3 FPDs were digitally fabricated and 1 FPD was conventionally fabricated. The sequence of the FPD assessment was randomly allocated according to a computer-generated list. To reduce operator bias, the investigators generated and evaluated the replicas without being able to distinguish among the digitally fabricated FPDs under investigation.

The clinical procedures were performed by 3 calibrated clinicians (G.B., S.M., I.S.). The clinicians were experienced with the digital impression systems tested and ceramic CAD-CAM restorations. The abutment teeth were prepared according to the guidelines for the fabrication of ceramic CAD-CAM restorations (Sturzenegger B, et al. Swiss Dent J 2000;110:131-9). At the subsequent clinical appointment, 3 digital impressions and 1 conventional impression were made for each participant. The description of the impression procedure is reported in part I of this investigation. $^{15}$

Three zirconia frameworks and 1 metal framework were fabricated for each participant. For the Lava (3M ESPE) workflow, optical impressions were made with the system-specific intraoral scanner (Lava chairside oral scanner [C.O.S.]; 3M ESPE), and frameworks were designed with 
the manufacturer's software (Lava C.O.S. Lab Software v3.0.2; 3M ESPE). Spacer thickness was set as recommended by the manufacturer (default setting for spacer: $70 \mu \mathrm{m}$ ). The restorations were milled from zirconia blocks (Lava zirconia; 3M ESPE) in a centralized milling center (Lava Milling Center by Rainer Rominger).

For the iTero workflow, the optical impressions were made with the iTero scanner (Align Technologies Inc), and the frameworks were designed with the CAD software (Cares Visual v6.2; Institut Straumann AG). Spacer thickness was set as recommended by the manufacturer (default setting for spacer: $70 \mu \mathrm{m}$ ). The restorations were milled from zirconia blocks (Zerion; Institut Straumann AG) in a centralized milling center (Institut Straumann AG). For the Cerec infiniDent workflow, the optical impressions were made with the Cerec Bluecam (Dentsply Sirona), and the frameworks were designed with the Cerec Connect software (v4.0.3; Dentsply Sirona) and the Cerec inLab 3D software (v4.0.3; Dentsply Sirona). Spacer thickness was set as recommended by the manufacturer (default setting for spacer: $60 \mu \mathrm{m})$. The frameworks were milled from zirconia blocks (inCoris ZI; Dentsply Sirona) in a centralized production center (infiniDent; Dentsply Sirona).

For the conventional workflow, impressions were made with a polyether material (Permadyne; 3M ESPE), and stone casts were poured (Type IV, Quadro-rock plus; Picodent). After a single application of die spacer (Chromo Spacer No. 1; Benzer Dental AG), a wax pattern (Inlay Wax Soft; GC Austria GmbH) of the framework was made manually. The frameworks were fabricated using the lost-wax technique and conventional casting procedure with a noble alloy (Estheticor Special; Cendre Métaux SA). The fabrication of all FPDs was executed by 1 calibrated dental technician. A detailed description of the technical workflow used for the fabrication of FPDs was reported in part II of this investigation. ${ }^{16}$ 
At the clinical evaluation appointment, 3 zirconia frameworks and 1 conventional framework were assessed. The dental technician was not allowed to manually adjust the frameworks on the respective cast. The description of the qualitative assessment of the framework is reported in part II of this investigation. ${ }^{16}$

The internal fit of the 3-unit frameworks was registered by means of the replica technique. ${ }^{13,20}$ The reconstructions were filled with a light-body polyvinyl siloxane (Coltène Affinis light-body; Coltène/Whaledent AG) and placed on the abutment teeth by applying finger pressure in the apical direction. After the impression material had polymerized, the framework was removed together with the polyvinyl siloxane film adhering to the intaglio surface. The thin layer of polyvinyl siloxane was stabilized by an injection of a heavy-body polyvinyl siloxane (Memosil; Kulzer $\mathrm{GmbH}$ ) into the framework. After setting, the polyvinyl siloxane materials were removed from the framework. The replica of each abutment tooth was sectioned mesiodistally and buccolingually into 4 parts. One calibrated investigator (M.Z.) performed the cutting procedure according to a standardized protocol and by means of a study-specific device to ensure the replicas of the same abutment tooth were sectioned in the same position (Figs. 1, 2). ${ }^{17}$ The thickness of the light-body polyvinyl siloxane representing the discrepancy between the framework and the abutment tooth was measured with a light microscope at $\times 200$ magnification (Keyence VHX-2000 digital microscope; Keyence Deutschland GmbH). One blinded and calibrated investigator (J.G.) measured all the specimens.

The internal discrepancy was assessed in 5 different regions of interest (Fig. 3).

Discrepancy marginal was defined as the distance between the points representing the preparation finish line and the restoration margin. Discrepancyshoulder was defined as the mean value of 4 measurements in the region representing the shoulder (1 measurement each $100 \mu \mathrm{m})$. 
Discrepancyaxial was defined as the mean value of 4 measurements in the region representing the axial wall (1 measurement each $250 \mu \mathrm{m})$, and Discrepancy cusp $_{\text {was }}$ defined as the mean value of 4 measurements in the region representing the cusp ( 1 measurement each $100 \mu \mathrm{m})$. The cusp was thereby characterized as the transition zone between the axial and occlusal surfaces.

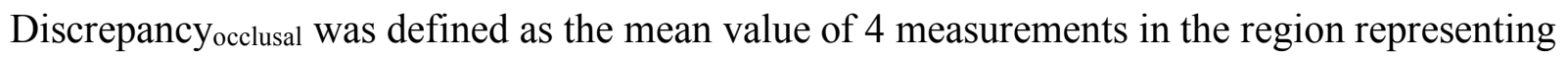
the occlusal surface ( 1 measurement each $250 \mu \mathrm{m})$. The specimens representing the mesial, buccal, distal, and lingual aspects of the abutment teeth were consecutively analyzed. Statistical software ( $\mathrm{R}^{21}$ and IBM SPSS Statistics v22.0; IBM Corp) were used for statistical analysis. The data distributions were reported with means, standard deviations, ranges, and 95\% confidence intervals. The R-package $1 \mathrm{me} 4^{22}$ was used to perform a linear mixed effects analysis of the relationship between internal gap (dependent variable in $\mu \mathrm{m}$ ) and the fixed effect factors treatment options (Conventional, Lava, Cerec infiniDent, iTero), the regions of interest (marginal, shoulder, axial, cusp, occlusal), the abutment teeth (mesial, distal), and the measurement locations (mesial, buccal, distal, lingual). To control for repeated measures, the intercept for participants was included as a random effects factor. $P$ values were obtained by likelihood ratio tests of the full model with the effect in question against the model without the effect in question.

If fixed factors or their interactions were statistically significant, the post hoc paired $t$ test with Bonferroni correction was performed $(\alpha=.05)$. In the case of significant interactions, the post hoc testing was performed for the included subgroups separately (Table 1). Visual inspection of residual plots did not reveal any obvious deviations from homoscedasticity. However, since visual inspection of residuals showed deviations from normality, a log 
transformation of the dependent variable (internal gap in $\mu \mathrm{m}$ ) was performed to approximate normal distribution for the linear mixed effect size model and the post hoc testing.

\section{RESULTS}

The internal gap measured $116.6 \pm 66.8 \mu \mathrm{m}$ for the iTero, $127.5 \pm 86.1 \mu \mathrm{m}$ for the conventional, $131.8 \pm 77.1 \mu \mathrm{m}$ for the Cerec infiniDent, and $140.0 \pm 102.5 \mu \mathrm{m}$ for the Lava workflow. A significant effect of the treatment option $(P<.001)$ was shown. The Cerec infiniDent $(P<.01)$ and the Lava $(P<.01)$ workflows produced significantly higher values compared with the iTero workflow.

A significant interaction of treatment option and region of interest $(P<.001)$, as well as of treatment option and abutment tooth, was encountered $(P<.001)$. Because of the significant interaction, pairwise comparison of different treatment options for each region of interest and for each abutment tooth was performed separately using paired $t$ tests. No other significant interactions were encountered.

Discrepancymarginal measured $91.4 \pm 95.2 \mu \mathrm{m}$ for the iTero, $106.4 \pm 103.7 \mu \mathrm{m}$ for the Lava, 108.3 $\pm 93.8 \mu \mathrm{m}$ for the Cerec infiniDent, and $117.7 \pm 129.4 \mu \mathrm{m}$ for the conventional workflow (Table 1). The differences between the treatment options were not statistically significant $(P>.05)$. Discrepancyshoulder was $96.1 \pm 61.7 \mu \mathrm{m}$ for the iTero; $106.9 \pm 96.0 \mu \mathrm{m}$ for the Lava, $112.2 \pm 76.7$ $\mu \mathrm{m}$ for the Cerec infiniDent, and $126.5 \pm 91.0 \mu \mathrm{m}$ for the conventional workflow (Table 1 ). The difference between the iTero and the conventional workflow was statistically significant $(P=.029)$. 
Regarding Discrepancyaxial, no significant differences were found among the treatment options $(P>.05)$. Discrepancy $_{a x i a l}$ was $93.1 \pm 28.5 \mu \mathrm{m}$ for the iTero, $105.8 \pm 37.7 \mu \mathrm{m}$ for the Lava, 114.7 $\pm 57.1 \mu \mathrm{m}$ for the Cerec infiniDent, and $106.8 \pm 47.4 \mu \mathrm{m}$ for the conventional workflow (Table 1). Discrepancy $_{\text {cusp }}$ was $149.1 \pm 50.1 \mu \mathrm{m}$ for the iTero, $175.7 \pm 82.2 \mu \mathrm{m}$ for the Lava, $142.4 \pm 68.7 \mu \mathrm{m}$ for the Cerec infiniDent, and $137.1 \pm 69.0 \mu \mathrm{m}$ for the conventional workflow (Table 1). The conventional and the Cerec infiniDent workflows produced significantly lower values of Discrepancy $_{\text {cusp }}$ compared with the Lava workflow $(P<.01)$.

Discrepancy $_{\text {occlusal }}$ measured $153.4 \pm 49.0 \mu \mathrm{m}$ for the iTero, $203.3 \pm 127.9 \mu \mathrm{m}$ for the Lava, 179.7 $\pm 63.0 \mu \mathrm{m}$ for the Cerec infiniDent, and $148.8 \pm 66.8 \mu \mathrm{m}$ for the conventional workflow (Table 1).

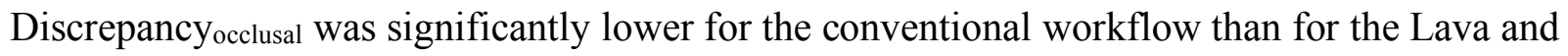
the Cerec infindent workflows $(P<.01)$. The iTero resulted in significantly lower values of Discrepancy $y_{\text {occlusal }}$ than the Lava and the Cerec infiniDent workflows $(P<.01)$.

The internal gap measured 106.6 $\pm .70 .1 \mu \mathrm{m}$ (mesial tooth) and $126.0 \pm 62.2 \mu \mathrm{m}$ (distal tooth) for the iTero, $119.8 \pm 75.0 \mu \mathrm{m}$ (mesial tooth) and $143.2 \pm 77.4$ (distal tooth) for the Cerec infiniDent, $129.5 \pm 102.2 \mu \mathrm{m}$ (mesial tooth) and 125.4 $\pm .66 .2 \mu \mathrm{m}$ (distal tooth) for the conventional, and $148.2 \pm 124.2$ (mesial tooth) and $131.8 \pm 74.0 \mu \mathrm{m}$ (distal tooth) for the Lava workflow. The differences between the mesial and distal tooth were statistically significant in the Cerec infiniDent $(P<.001)$ and in the iTero workflows.

\section{DISCUSSION}

The digitally fabricated zirconia 3-unit FPD frameworks had a similar or better fit in the shoulder region than the conventionally fabricated metal frameworks. The metal frameworks showed the highest average values of discrepancy in the shoulder region followed by Cerec infiniDent, Lava, 
and iTero. In the occlusal regions, the conventionally fabricated metal FPD frameworks achieved a more favorable fit compared with the CAD-CAM zirconia frameworks.

Several in vitro and clinical studies have assessed the accuracy of FPDs. ${ }^{9-13}$ An in vitro study compared the accuracy of CAD-CAM zirconia 3-unit FPDs made by means of Lava, Procera, and Cerec workflows with that of conventional metal-ceramic FPDs. ${ }^{9}$ The conventional metalceramic FPDs had the highest average values of marginal discrepancy followed by the Lava, the Cerec, and the Procera zirconia FPDs. It was concluded that the marginal discrepancies for zirconia restorations were significantly smaller than those for the metal-ceramic FPDs. Another in vitro trial compared the marginal fit of zirconia 3-unit FPDs made using Everest and Lava CAD-CAM systems with that of metal-ceramic FPDs. ${ }^{11}$ The Everest group produced the lowest values of the mean marginal gap followed by the Lava group and by the metal-ceramic group. The Everest group demonstrated significantly smaller marginal discrepancy values than the Lava or the metal-ceramic groups. The marginal discrepancy did not significantly differ between the Lava and the metal-ceramic groups. A recent in vitro study evaluated the marginal fit of digitally fabricated zirconia FPD frameworks and conventionally fabricated metal frameworks. ${ }^{10}$ The FPDs fabricated with CAD-CAM workflows showed less discrepancy than the frameworks obtained with the conventional workflow. The lowest mean values of discrepancy were found for the iTero group followed by the $3 \mathrm{~S}$ and the Cerec groups. The results of these investigations are consistent with the findings of the present trial.

A previous randomized controlled clinical trial assessed the accuracy of 16 conventional metal-ceramic 3-unit FPDs with that of 16 CAM zirconia FPDs. ${ }^{13}$ The test zirconia frameworks were fabricated by means of wax-up, scanning, and milling with the Cercon system. The accuracy values reported for the metal FPDs corresponded well with the values found for the 
metal frameworks in the present study. The zirconia CAM frameworks produced significantly lower accuracy in comparison with the conventional metal frameworks. The lower accuracy of the zirconia FPDs might be explained by the semidigital fabrication option and the type of milling unit. Other studies found lower accuracy for restorations fabricated through a CAM workflow in comparison with those produced by using a CAD-CAM workflow. ${ }^{23,24}$ The fact that digitally fabricated zirconia FPDs produced similar or better marginal accuracy than the conventional frameworks is clinically relevant. Based on these findings, zirconia FPDs fabricated by using fully digital workflows should perform similarly or better than conventional metal FPDs regarding resistance to marginal microleakage and caries. Because of the high intrinsic stability of zirconia, the poor occlusal fit of the CAD-CAM zirconia FPDs is probably not clinically relevant. The clinical implications of the results from the present investigation have not been sufficiently assessed. Future studies should assess the long-term clinical performance of CAD-CAM FPDs.

\section{CONCLUSIONS}

Within the limitations of the present clinical study on tooth-supported posterior 3-unit fixed dental prostheses, the following conclusions were drawn:

1. In terms of accuracy in the region of the shoulder, digitally fabricated zirconia frameworks presented similar or better fit than the conventionally fabricated metal frameworks.

In the occlusal regions, the conventionally fabricated metal frameworks achieved a more favorable fit compared with the CAD-CAM zirconia frameworks. 


\section{REFERENCES}

1. Molin MK, Karlsson SL. Five-year clinical prospective evaluation of zirconia-based Denzir 3unit FPDs. Int J Prosthodont 2008;21:223-7.

2. Schmitt J, Holst S, Wichmann M, Reich S, Gollner M, Hamel J. Zirconia posterior fixed partial dentures: a prospective clinical 3-year follow-up. Int J Prosthodont 2009;22:597-603.

3. Sailer I, Feher A, Filser F, Gauckler LJ, Luthy H, Hammerle CH. Five-year clinical results of zirconia frameworks for posterior fixed partial dentures. Int J Prosthodont 2007;20:383-8.

4. Eschbach S, Wolfart S, Bohlsen F, Kern M. Clinical evaluation of all-ceramic posterior threeunit FDPs made of In-Ceram Zirconia. Int J Prosthodont 2009;22:490-2.

5. Beschnidt SM, Strub JR. Evaluation of the marginal accuracy of different all-ceramic crown systems after simulation in the artificial mouth. J Oral Rehabil 1999;26:582-93.

6. Jacobs MS, Windeler AS. An investigation of dental luting cement solubility as a function of the marginal gap. J Prosthet Dent 1991;65:436-42.

7. Rekow D, Thompson VP. Near-surface damage--a persistent problem in crowns obtained by computer-aided design and manufacturing. Proc Inst Mech Eng H 2005;219:233-43.

8. Tuntiprawon M, Wilson PR. The effect of cement thickness on the fracture strength of allceramic crowns. Aust Dent J 1995;40:17-21.

9. Gonzalo E, Suarez MJ, Serrano B, Lozano JF. A comparison of the marginal vertical discrepancies of zirconium and metal ceramic posterior fixed dental prostheses before and after cementation. J Prosthet Dent 2009;102:378-84.

10. Mello C, Santiago Junior JF, Galhano G, Quinelli Mazaro JV, Scotti R, Pellizzer E. Analysis of vertical marginal adaptation of zirconia fixed dental prosthesis frameworks fabricated by the CAD/CAM system: a randomized, double-blind study. Int J Prosthodont 2016;29:157-60. 
11. Song TJ, Kwon TK, Yang JH, Han JS, Lee JB, Kim SH et al. Marginal fit of anterior 3-unit fixed partial zirconia restorations using different CAD/CAM systems. J Adv Prosthodont $2013 ; 5: 219-25$.

12. Su TS, Sun J. Comparison of marginal and internal fit of 3-unit ceramic fixed dental prostheses made with either a conventional or digital impression. J Prosthet Dent 2016;116:3627.

13. Wettstein F, Sailer I, Roos M, Hammerle CH. Clinical study of the internal gaps of zirconia and metal frameworks for fixed partial dentures. Eur J Oral Sci 2008;116:272-9.

14. Abduo J, Lyons K, Swain M. Fit of zirconia fixed partial denture: a systematic review. J Oral Rehabil 2010;37:866-76.

15. Sailer I, Mühlemann S, Fehmer V, Hammerle CHF, Benic GI. Randomized controlled clinical trial of digital and conventional workflows for the fabrication of zirconia-ceramic fixed partial dentures. Part I: Complete-arch digital scans versus conventional impressions. J Prosthet Dent 2018; In press.

16. Sailer I, Benic GI, Fehmer V, Hämmerle CHF, Mühlemann S. Randomized controlled clinical trial of digital and conventional workflows for the fabrication of zirconia-ceramic posterior fixed partial dentures. Part II: CAD-CAM versus conventional laboratory procedures. J Prosthet Dent 2017;118:43-8.

17. Zeltner M, Sailer I, Mühlemann S, Ozcan M, Hämmerle CH, Benic GI. Randomized controlled within-subject evaluation of digital and conventional workflows for the fabrication of lithium disilicate single crowns. Part III: marginal and internal fit. J Prosthet Dent 2017; 117:35462. 
18. Benic GI, Muhlemann S, Fehmer V, Hammerle CH, Sailer I. Randomized controlled withinsubject evaluation of digital and conventional workflows for the fabrication of lithium disilicate single crowns. Part I: digital versus conventional unilateral impressions. J Prosthet Dent 2016;116:777-82.

19. Sailer I, Benic GI, Fehmer V, Hammerle CHF, Muhlemann S. Randomized controlled within-subject evaluation of digital and conventional workflows for the fabrication of lithium disilicate single crowns. Part II: CAD-CAM versus conventional laboratory procedures. J Prosthet Dent 2017;118:43-8.

20. Boening KW, Wolf BH, Schmidt AE, Kastner K, Walter MH. Clinical fit of Procera AllCeram crowns. J Prosthet Dent 2000;84:419-24.

21. R Development Core Team. A language and environment for statistical computing. $\mathrm{R}$ Foundation for Statistical Computing. Vienna, Austria 2012

22. Bates D, Machler M, Bolker BM, Walker SC. Fitting linear mixed-effects models using lme4. J Stat Softw 2015;67:1-48.

23. Beuer F, Aggstaller H, Edelhoff D, Gernet W, Sorensen J. Marginal and internal fits of fixed dental prostheses zirconia retainers. Dent Mater 2009;25:94-102.

24. Bindl A, Mormann WH. Fit of all-ceramic posterior fixed partial denture frameworks in vitro. Int J Periodontics Restorative Dent 2007;27:567-75. 


\section{TABLES}

Table 1. Discrepancy values $(\mu \mathrm{m})$ in 5 different regions of interest (marginal, shoulder, axial, cusp, occlusal) for each treatment option (Conventional, Lava, Cerec infiniDent, iTero). Superscript $(\dagger)$ represents statistically significant difference $(P<.05)$ between

treatments (post hoc paired $t$ test with Bonferroni correction)

\begin{tabular}{|c|c|c|c|c|c|c|c|c|c|c|c|c|}
\hline \multirow{2}{*}{\begin{tabular}{|l|}
$\begin{array}{l}\text { Treatment } \\
\text { option }\end{array}$ \\
$\begin{array}{l}\text { Region of } \\
\text { interest }\end{array}$
\end{tabular}} & \multicolumn{3}{|c|}{ Conventional } & \multicolumn{3}{|c|}{ Lava } & \multicolumn{3}{|c|}{ Cerec infiniDent } & \multicolumn{3}{|c|}{ iTero } \\
\hline & $\begin{array}{l}\text { Mean } \\
\pm \text { SD } \\
\text { (Median) }\end{array}$ & $\begin{array}{l}\text { 95\% CI } \\
\text { (Range) }\end{array}$ & $P$ & \begin{tabular}{|l} 
Mean \\
\pm SD \\
(Median)
\end{tabular} & $\begin{array}{l}\text { 95\% CI } \\
\text { (Range) }\end{array}$ & $P$ & \begin{tabular}{|l} 
Mean \\
\pm SD \\
(Median)
\end{tabular} & $\begin{array}{l}\text { 95\% CI } \\
\text { (Range) }\end{array}$ & $P$ & $\begin{array}{l}\text { Mean } \\
\pm \text { SD } \\
\text { (Median) }\end{array}$ & $\begin{array}{l}\text { 95\% CI } \\
\text { (Range) }\end{array}$ & $P$ \\
\hline Marginal & $\begin{array}{l}117.7 \\
\pm 129.4 \\
(87.5)\end{array}$ & \begin{tabular}{|l|}
$114.4-121.0$ \\
$(13.0-394.0)$
\end{tabular} & $\begin{array}{l}\text { Lava }>.1 \\
\text { Cerec infiniDent }>.1 \\
\text { iTero }>.1\end{array}$ & \begin{tabular}{|l}
106.4 \\
\pm 103.7 \\
$(75.0)$
\end{tabular} & \begin{tabular}{|l|}
$103.6-109.2$ \\
$(23.0-482.0)$
\end{tabular} & $\begin{array}{l}\text { Conventional }>.1 \\
\text { Cerec infiniDent }>.1 \\
\text { iTero }>.1\end{array}$ & $\begin{array}{l}108.3 \\
\pm 93.8 \\
(72.5)\end{array}$ & $\begin{array}{l}105.7-110.9 \\
(18.0- \\
491.00)\end{array}$ & $\begin{array}{l}\text { Conventional }>.1 \\
\text { Lava }>.1 \\
\text { iTero }>.1\end{array}$ & $\begin{array}{l}91.4 \\
\pm 95.2 \\
(65.0)\end{array}$ & $\begin{array}{l}88.9-93.9 \\
(16-425.5)\end{array}$ & $\begin{array}{l}\text { Conventional }>.1 \\
\text { Lava }>.1 \\
\text { Cerec infiniDent }>.1\end{array}$ \\
\hline Shoulder & $\begin{array}{l}126.5 \\
\pm 91 \\
(105.5)\end{array}$ & $\begin{array}{l}124.3-128.7 \\
(27.8-331.8)\end{array}$ & $\begin{array}{l}\text { Lava }>.1 \\
\text { Cerec infiniDent }>.1 \\
\text { iTero }=.029 \dagger\end{array}$ & $\begin{array}{l}106.9 \pm 96 \\
(73.0)\end{array}$ & \begin{tabular}{|l|}
$104.5-109.3$ \\
$(28.0-464.5)$
\end{tabular} & $\begin{array}{l}\text { Conventional }>.1 \\
\text { Cerec infiniDent }>.1 \\
\text { iTero }>.1\end{array}$ & $\begin{array}{l}112.2 \\
\pm 76.7 \\
(87.8)\end{array}$ & $\begin{array}{l}110.3-114.1 \\
(30.0-409.0)\end{array}$ & $\begin{array}{l}\text { Conventional }>.1 \\
\text { Lava }>.1 \\
\text { iTero }>.1\end{array}$ & $\begin{array}{l}96.1 \\
\pm 61.7 \\
(80.5)\end{array}$ & $\begin{array}{l}94.6-97.6 \\
(26.5-416.5)\end{array}$ & $\begin{array}{l}\text { Conventional }=.029 \dagger \\
\text { Lava }>.1 \\
\text { Cerec infiniDent }>.1\end{array}$ \\
\hline Axial & $\begin{array}{l}106.8 \\
\pm 47.4 \\
(99.3)\end{array}$ & $\begin{array}{l}105.6-108.0 \\
(35.8-300.5)\end{array}$ & $\begin{array}{l}\text { Lava }>.1 \\
\text { Cerec infiniDent }>.1 \\
\text { iTero }>.1\end{array}$ & $\begin{array}{l}105.8 \\
\pm 37.6 \\
(101.0)\end{array}$ & $\begin{array}{l}104.9-106.7 \\
(37.0-225.8)\end{array}$ & $\begin{array}{l}\text { Conventional }>.1 \\
\text { Cerec infiniDent }>.1 \\
\text { iTero }>.1\end{array}$ & $\begin{array}{l}114.7 \\
\pm 57.1 \\
(99.0)\end{array}$ & $\begin{array}{l}113.3-116.1 \\
(36.8-264.3)\end{array}$ & $\begin{array}{l}\text { Conventional }>.1 \\
\text { Lava }>.1 \\
\text { iTero }>.1\end{array}$ & $\begin{array}{l}93.1 \\
\pm 28.5 \\
(94.8)\end{array}$ & $\begin{array}{l}92.4-93.8 \\
(34.8-183.3)\end{array}$ & $\begin{array}{l}\text { Conventional }>.1 \\
\text { Lava }>.1 \\
\text { Cerec infiniDent }>.1\end{array}$ \\
\hline Cusp & \begin{tabular}{|l}
137.1 \\
\pm 69 \\
$(119.8)$
\end{tabular} & \begin{tabular}{|l|}
$135.3-138.9$ \\
$(27.5-325.0)$
\end{tabular} & $\begin{array}{l}\text { Lava }<.001 \dagger \\
\text { Cerec infiniDent }>.1 \\
\text { iTero }>.1\end{array}$ & $\begin{array}{l}175.7 \\
\pm 82.2 \\
(153.8)\end{array}$ & \begin{tabular}{|l|}
$173.6-177.8$ \\
$(66.0-526.8)$
\end{tabular} & $\begin{array}{l}\text { Conventional }<.001 \dagger \\
\text { Cerec infiniDent }<.005 \dagger \\
\text { iTero }>.1\end{array}$ & $\begin{array}{l}142.4 \\
\pm 68.7 \\
(131.4)\end{array}$ & $\begin{array}{l}140.7-144.1 \\
(47.5-349.0)\end{array}$ & $\begin{array}{l}\text { Conventional }>.1 \\
\text { Lava }<.005 \dagger \\
\text { iTero }>.1\end{array}$ & \begin{tabular}{|l}
149.1 \\
\pm 50.8 \\
$(140.6)$
\end{tabular} & $\begin{array}{l}147.8-150.4 \\
(74-295.8)\end{array}$ & $\begin{array}{l}\text { Conventional }>.1 \\
\text { Lava }>.1 \\
\text { Cerec infiniDent }>.1\end{array}$ \\
\hline Occlusal & $\begin{array}{l}148.8 \\
\pm 66.8 \\
(140.3)\end{array}$ & \begin{tabular}{|l}
$147.1-150.5$ \\
$(31.5-354.3)$
\end{tabular} & $\begin{array}{l}\text { Lava }<.001 \dagger \\
\text { Cerec infiniDent } \\
=.006 \dagger \\
\text { Tero }>.1\end{array}$ & \begin{tabular}{|l}
203.3 \\
\pm 127.9 \\
$(162.0)$
\end{tabular} & \begin{tabular}{|l|}
$200.1-206.5$ \\
$(98.0-752.3)$
\end{tabular} & $\begin{array}{l}\text { Conventional }<.001 \dagger \\
\text { Cerec infiniDent }>.1 \\
\text { iTero }=.016 \dagger\end{array}$ & $\begin{array}{l}179.7 \\
\pm 63.1 \\
(169.4)\end{array}$ & $\begin{array}{l}178.1-181.3 \\
(67.5-389.5)\end{array}$ & $\begin{array}{l}\text { Conventional }=.006 \dagger \\
\text { Lava }>.1 \\
\text { iTero }<.005 \dagger\end{array}$ & $\begin{array}{l}153.5 \\
\pm 66.8 \\
(149.9)\end{array}$ & $\begin{array}{l}152.3-154.7 \\
(34.8-296.5)\end{array}$ & $\begin{array}{l}\text { Conventional }>.1 \\
\text { Lava }=.016 \dagger \\
\text { Cerec infiniDent }< \\
.005 \dagger\end{array}$ \\
\hline
\end{tabular}




\section{FIGURES}

Figure 1. Embedded silicone layer (replica) sectioned mesiodistallly and buccolingually for each abutment tooth: $\mathrm{m}$, mesial; $d$, distal; $b$, buccal; 1 , lingual

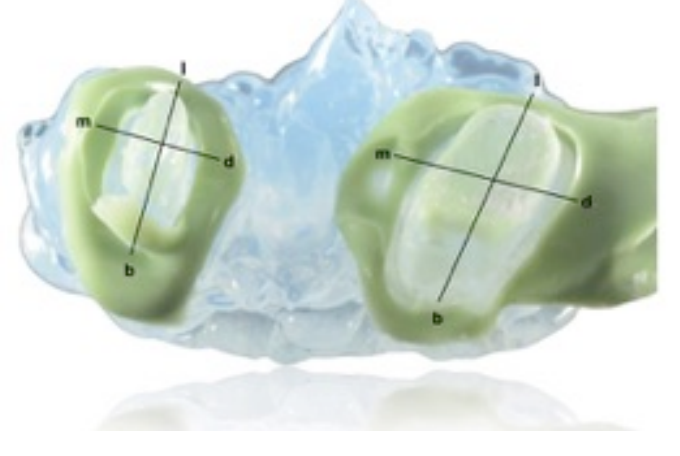

Figure 2. Study-specific cutting device with orthogonally mounted surgical blades and engaging carrier allowing standardized cutting of replicas.

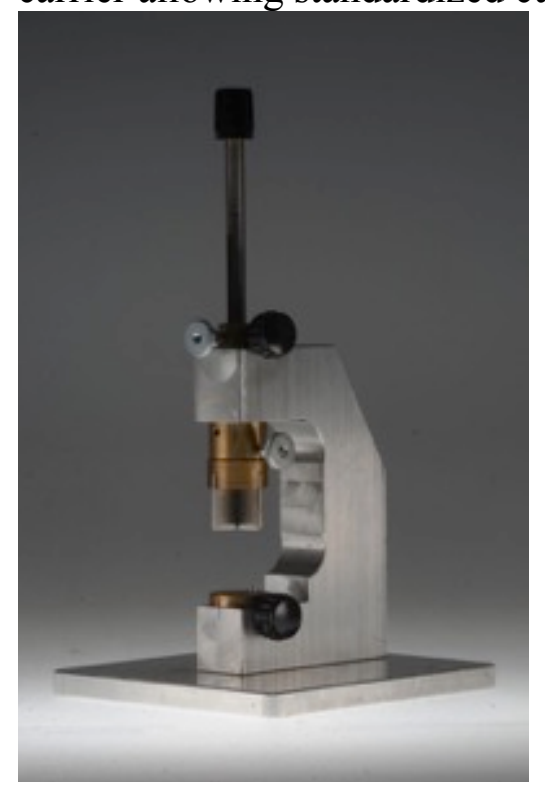

Figure 3 Regions of interest. A, Cross-section of replica. B, Discrepancy shoulder. C, $_{\text {, }}$

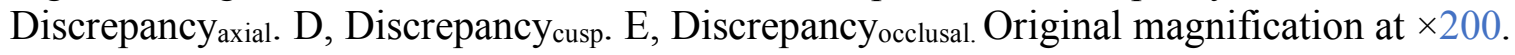
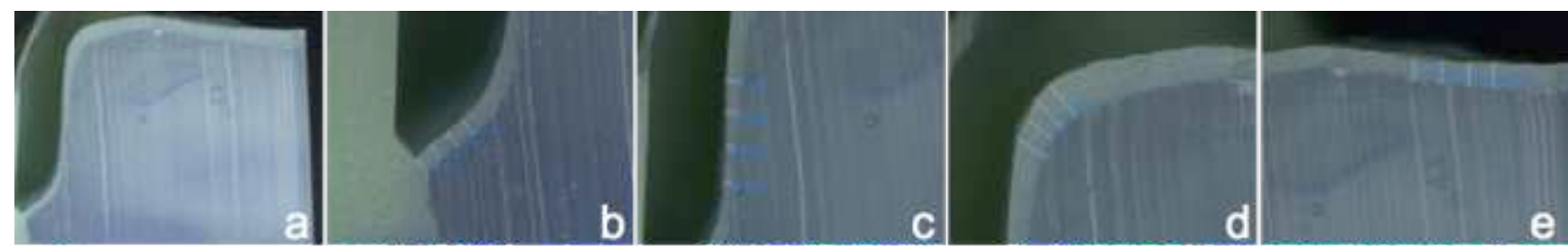